\title{
Greenhouse industry 4.0 - digital twin technology for commercial greenhouses
}

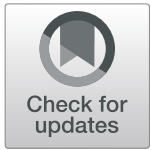

\author{
Daniel Anthony Howard ${ }^{1 *}$, Zheng Ma², Christian Veje ${ }^{1}$, Anders Clausen ${ }^{1}$, Jesper Mazanti Aaslyng ${ }^{3}$ and \\ Bo Nørregaard Jørgensen ${ }^{1}$
}

From 1st Energy Informatics. Academy Conference Asia

Beijing, China. 29-30 May 2021

\footnotetext{
*Correspondence: danho@mmmi. sdu.dk

${ }^{1}$ SDU Center for Energy Informatics, Mærsk McKinney Møller Institute, University of Southern Denmark, Campusvej 55, DK-5230 Odense M, Denmark

Full list of author information is available at the end of the article
}

\begin{abstract}
The project aims to create a Greenhouse Industry 4.0 Digital Twin software platform for combining the Industry 4.0 technologies (IoT, Al, Big Data, cloud computing, and Digital Twins) as integrated parts of the greenhouse production systems. The integration provides a new disruptive approach for vertical integration and optimization of the greenhouse production processes to improve energy efficiency, production throughput, and productivity without compromising product quality or sustainability. Applying the Industry 4.0 Digital Twin concept to the Danish horticulture greenhouse industry provides digital models for simulating and evaluating the physical greenhouse facility's performance. A Digital Twin combines modeling, Al, and Big Data analytics with loT and traditional sensor data from the production and cloud-based enterprise data to predict how the physical twin will perform under varying operational conditions. The Digital Twins support the cooptimization of the production schedule, energy consumption, and labor cost by considering influential factors, including production deadlines, quality grading, heating, artificial lighting, energy prices (gas and electricity), and weather forecasts. The ecosystem of digital twins extends the state-of-the-art by adopting a scalable distributed approach of "system of systems" that interconnects Digital Twins in a production facility. A collection of specialized Digital Twins are linked together to describe and simulate all aspects of the production chain, such as overall production capacity, energy consumption, delivery dates, and supply processes. The contribution of this project is to develop an ecosystem of digital twins that collectively capture the behavior of an industrial greenhouse facility. The ecosystem will enable the industrial greenhouse facilities to become increasingly active participants in the electricity grid.
\end{abstract}

Keywords: Greenhouse, Industry 4.0, Digital twin, Energy flexibility, Artificial intelligence

\section{Introduction}

As the world has seen an increasing penetration of intermittent renewable energy sources to combat global warming, there has been a call for solutions that can support

(c) The Author(s). 2021 Open Access This article is licensed under a Creative Commons Attribution 4.0 International License, which permits use, sharing, adaptation, distribution and reproduction in any medium or format, as long as you give appropriate credit to the original author(s) and the source, provide a link to the Creative Commons licence, and indicate if changes were made. The images or other third party material in this article are included in the article's Creative Commons licence, unless indicated otherwise in a credit line to the material. If material is not included in the article's Creative Commons licence and your intended use is not permitted by statutory regulation or exceeds the permitted use, you will need to obtain permission directly from the copyright holder. To view a copy of this licence, visit http://creativecommons.org/licenses/by/4.0/. 
the electricity grid's balancing. The energy system has traditionally followed the consumers' demand by regulating the power plants' operation (Qingnan Li and Jørgensen 2016). However, as intermittent renewable energy sources are being introduced into the energy system while phasing out large coal-fired power plants, there is a need for active market players that can adjust their consumption based on market conditions (Mlecnik et al. 2019). A solution that aids in grid stability is demand response, in which the participants adjust their consumption based on price signals or market conditions (Ma et al. 2017a). Based on their consumption and adjustment speed, the consumers can act in various parts of the market based on the met conditions. The greenhouse industry has been identified as a consumer group with significant potential for delivering demand response as they have high electricity consumption and already installed energy management systems and should be prioritized (Müller and Möst 2018; Ma and Jørgensen 2018). However, industries have in general expressed concerns about flexible energy consumption implications on their products' production and quality (Haeri et al. 2018).

Based on the previous work presented in (Markvart et al. 2008; Sørensen et al. 2016), a national project called the Greenhouse Industry 4.0 (GHI4.0), funded by the Danish Energy Technology Development and Demonstration Program (EUDP Project no 64019-0018) with a project period of 2019 to 2022., aims to make the Danish horticultural greenhouse industry production energy-efficient and environmentally sustainable. GHI4.0 will enable energy-aware and sustainable production by adapting and combining the Industry 4.0 (I4.0) principal technologies; Internet of Things (IoT), Artificial Intelligence (AI), Big Data, cloud computing, and Digital Twins (DT) as integrated parts of their production systems. Similar to other energy and labor-intensive industries that compete with low-cost regions, such as cement production (Ma et al. 2017b), the Danish horticultural greenhouse industry must continuously improve energy efficiency and production throughput, and productivity without compromising product quality or sustainability to stay competitive. The research presents a new disruptive approach for vertically integrating and optimizing the greenhouse production processes. Using DT technology, the Danish horticultural greenhouse industry will become increasingly competitive. Thereby securing their position against low-cost production regions globally, which are currently gaining access to the multi-billion global market for horticultural products. Furthermore, GHI4.0 will present a case study for assessing demand response potential while considering implications on the entire production chain. Hence, the project presents a novel way of considering demand response flexibility potential in terms of risk to production, aligned with the facility risk willingness. GHI4.0 will, in turn, enable the greenhouse facilities to become integrated consumers on the electricity grid that support the operation and stability of the future electricity grid (Clausen et al. 2015a; Christensen et al. 2020a).

Based on the I4.0 enabled DT concept, the Danish horticulture greenhouse industry will be equipped with digital models to simulate and evaluate the physical greenhouse facility's performance and production processes. A DT combines modeling, AI, and Big Data analytics with IoT supported by traditional production-based sensor data and cloud-based enterprise data as a foundation for predicting the physical twin behavior subjected to different operational conditions. Deploying the DT concept enables the greenhouse facility to co-optimize its production schedule, energy consumption, and 
labor cost accounting for influential factors, including production deadlines, quality grading, heating, artificial lighting, energy prices (gas and electricity), and weather forecasts.

The presented GHI4.0 research project will result in a DT software platform deployed and demonstrated at the participating greenhouse growers. The software platform will be made available, nationally and internationally, for greenhouse growers on commercial terms. Furthermore, the project will develop a framework that can be used autonomously of production system for developing DTs that will further enhance industrial participation in the energy system.

\section{Background}

GHI4.0 builds on Industry 4.0 concepts that are the key enabling technologies for the project. I4.0 is the fourth industrial revolution, which is characterized by the full automation and digitization of processes as well as the use of electronics and information technologies (IT) in manufacturing and services (Roblek et al. 2016). I4.0 aims to combine the real and virtual space to achieve maximum efficiency and autonomy in production processes and industries through cyber-physical systems (Huang et al. 2017). It encompasses digitalization technologies such as the IoT, cyber-physical systems (CPS), AI, and Information and Communication Technologies (ICT). The use of digitalization technologies enabled virtual product and process planning. There is a need for detailed real-time data covering products and processes to be cost-effective for improving companies' productivity and energy security (Seow et al. 2013). I4.0 entails large amounts of processed, analyzed, and evaluated data by simulation and optimization tools (Rosen et al. 2015). One of these simulation-based planning and optimization concepts with great potential in many industrial fields is the DT (Tao et al. 2018).

A DT is established as a critical enabler for digital transformation. It is used to represent the complete digital footprints (states) of existing systems and allow, e.g., business managers to understand and assess the consequences and benefits before making decisions hence mitigating any risks (AnyLogic 2017). Due to different nature and varying integration levels of DT concepts, the set of technologies needed for the implementation differs significantly. Often referred technologies include simulation/modeling methods, communication protocols, and other I4.0 technologies (IoT, Cloud Computing, Big Data, etc.) (Kritzinger et al. 2018).

DTs have started seeing the more effective implementation in recent years for aiding companies in optimizing parts of their production. However, as an increasing number of DTs are developed in industries, and multiple DTs may be developed within a single company to represent several processes, a standardized DT interaction process will be required. The interaction will be necessary for future DT ecosystems as one DT's behavior may influence or propagate into another DT. Therefore, GHI4.0 will develop a standardized approach for connecting multiple DTs into a DT ecosystem that collectively constitutes the facility operation.

\section{State-of-art}

Currently, the state-of-the-art for DTs used in the manufacturing industry is limited to specific subprocesses modeled with highly specialized models. DTs of greenhouse production flows can provide an opportunity for simulating and optimizing the production 
system, including its logistical aspects. It enables detailed visualization of the production process from single components to the whole assembly (Kritzinger et al. 2018). The three main disciplines of production systems simulated in a DT are production planning and control (Rosen et al. 2015), maintenance (D'Addona et al. 2017), and layout planning (Uhlemann et al. 2017). Various simulation methods are applied for the production flow simulation, e.g., discrete event simulation and continuous simulation. However, singlehandedly, one approach is not advanced enough to represent a DTs complexity and dynamics. Multi-agent systems (MAS) simulation is a solution for governing complex and dynamic systems with many potential conflicting requirements (Ma et al. 2019). MAS simulation can solve difficult or computationally intractable problems; MAS can include intelligent methodic, functional, procedural approaches, algorithmic search, or reinforcement learning. MAS simulation is widely used in the simulation of manufacturing and business processes, and therefore well suited for simulating greenhouse production flows (Christensen et al. 2020b; Ma et al. 2020; Howard et al. 2021). Based on a detailed comparison of 20 simulation software products, this research project decided to use the commercial software package AnyLogic. AnyLogic is a multi-method general-purpose simulation tool that has been applied in various domains, including the simulation of physical energy systems, e.g., electricity production (Herrmann et al. 2011; Morvaj et al. 2011).

Intelligent use of greenhouse technology has been demonstrated in prototypes of automatic climate control systems (software and hardware) based on mathematical models of greenhouse technology, greenhouse climate, and crop physiology. Furthermore, recent advances in dynamic models for the utilization of supplemental artificial lighting based on weather forecasts and energy prices, which balance the electricity use with the state of the electricity grid, adds to the complexity (Sørensen et al. 2016; Kjaer et al. 2012; Clausen et al. 2015b). Several planning tools have been developed to provide growers with decision support for optimizing greenhouse climate control and managing production (Fisher and Heins 1996; Frantz et al. 2010; Körner et al. 2008; Vanthoor 2011; Kjaer et al. 2011). For instance, the first Danish commercial approach of an online decision support system, InfoGrow, developed by Agrotech (Körner and Hansen 2012) and currently upgraded in the ItGrows 2.0 (Kjaer et al. 2018), is a model-based decision support system for greenhouse energy management. Another software called DynaLight, developed by the University of Southern Denmark uses multi-objective optimization for energy cost-efficient artificial lighting control. The dynamic climate control in InfoGrow and the system DynaLight is based on predictive modeling and optimization (Sørensen et al. 2019). Control systems relying on models for predictions are often referred to as Model Predictive Control (MPC). MPC uses digital models of physical systems and optimization methods and predictions regarding future conditions (e.g., climatic) to find the most optimal control strategy. Such models can be developed based on technical documentation, reducing the dependence on actual measurements.

Energy is one important part of greenhouse production. Digital and numerical modeling is a well-established technology in energy systems, and its incorporation into an I4.0 framework is considered a medium complexity task due to its maturity (Frank et al. 2019). The models are physics-based or use a mix of physics- and data-driven approaches. Sensor data is used to calibrate the models, whereas the models optimize energy systems' operation (Frank et al. 2019). The recent trend in energy systems 
modeling uses gray-box models, including the modeled process's fundamental physical relationship but still relies on sensor data for calibration (Afroz et al. 2018). Often it is argued that gray-box modeling provides the most attractive balance between accuracy, computational speed, and scalability (Arendt et al. 2018a). Furthermore, the gray-box approach is widely used in MPC, especially for indoor climate control (Blum et al. 2019). Gray-box modeling requires a suitable parameter estimation technique. Typically, a global optimization method is required because even in simple models, the parameter estimation is a non-convex problem. However, further fine-tuning of the parameters using gradient-based methods is advised (Arendt et al. 2018b).

Currently, the greenhouse production is not combined with I4.0 standards and does not benefit from the production flow's combined optimization. The varying I4.0 technologies (IoT, AI, Big Data, cloud computing, and DTs) serve different purposes in I4.0. Industrial standards do not integrate current greenhouse production approaches, and the combination of different DTs is missing. To ensure communication between the developed DTs, a system must share state- and operational data (Howard et al. 2020). Using a common information model (CIM) creates common abstractions of domain entities and their relationships. Such CIM also presents the abstractions of information that the DTs can exchange. The specification of communication protocols is included to enable information exchange in software applications (Kritzinger et al. 2018). CIM has been adopted in the field of electricity transmission and distribution. It describes ontology, terminology, and relations between entities in the power grid to allow software applications in this context to exchange information. CIM has been standardized through the IEC 61970/61968 standards and extended into the domain of energy market communications in IEC 62325. CIM enables communication across several heterogeneous applications, including SCADA systems, planning, and optimization systems in the domains of electricity transmission, distribution, and market.

During the last 20 years, several projects have focused on different aspects of energy optimization in the greenhouse production system. Either the focus has been on implementing new technologies, e.g., infrastructures (glass and screen types), light-emitting diodes, or other types of equipment. Previous projects have focused on developing various IT and decision support systems for improved climate control, which balances the optimal plant photosynthesis and growth (or transpiration) with energy usage and cost (Rytter et al. 2012).

However, there is a lack of relationship between morphological plant development and the optimization of energy use. The greenhouse facilities currently operate energy optimization, product flow, and artificial climate as three separate systems. In practice, these systems in greenhouse productions are undoubtedly linked.

To fill this gap, the GHI4.0 project is the first research project that aims to create an ecosystem of DTs that operate based on the I4.0 enabling technologies. Thereby utilizing the greenhouse IoT devices, big data, and artificial intelligence for sustainable efficient, and high-quality greenhouse production and business. A holistic approach that takes the three objectives (production, energy, and climate) into consideration and optimized by integrating the three DTs. Meanwhile, the integrated DT can facilitate various what-if investigations, e.g., energy flexibility with electricity market participation and distributed energy resources. Furthermore, the developed DT allows growers to test their strategies, such as balancing between potential savings and risk, participantion in the energy flexibility markets. 


\section{Project aim and objectives}

GHI4.0 aims to improve the Danish greenhouses' energy efficiency and productivity by implementing I4.0 technologies. GHI4.0 will demonstrate the application of the I4.0 DT concept for modeling and simulating the physical greenhouse facility, including the production processes and flow, which can support greenhouse growers in decisionmaking that seeks to optimize production throughput and energy use. By implementing I4.0 in the horticultural greenhouse, the industry will benefit from improved productivity and energy cost-efficiency while supporting the UN global goals for affordable and clean energy (SDG 7), together with Industry, Innovation, and Infrastructure (SDG 9). The I4.0 DT concept application will introduce and combine mathematical models and simulation, AI, IoT sensors, cloud computing, and Big Data analytics to the Danish horticulture greenhouse industry.

The primary purpose of the GHI4.0 project is to:

1) Combine Industry 4.0 and AI technologies to build a DT ecosystem that supports deployment of research results to promote sustainable greenhouse production,

2) Investigate the energy and production effects of deploying I4.0 and DT technologies in greenhouse production.

The following research objectives are designed to reach the project goal:

- Develop three DTs covering the greenhouse climate compartments, production flow, and energy system.

- Establish a Common Information Model that serves as a single horizontal integration point for new software.

- Test the DTs at the three participating greenhouse facilities and report the observed effects.

The unique, innovative approach and functionality of the GHI4.0 project is to enable Danish greenhouse growers to become sustainable and flexible users of the energy grids (electricity, district heating, gas). Furthermore, the project also aims to show both the possibilities and the challenges in including complex energy demanding and energyproducing industry with high flexibility on the smart grid. Based on the proof-ofconcept in participating greenhouses, the case will advance the Danish greenhouse industry and lead the way for other industries and businesses to take advantage of the knowledge and technology developed in the project.

\section{Project methodology}

The overall project system can be seen in Fig. 1. As seen from Fig. 1, a DT is developed for each of the three greenhouse sections: the climate compartment, energy system, and production flow. All the DTs communicate through a developed CIM that exchanges information with a dashboard. The connection of multiple DTs within a single facility provides a novel approach for a distributed DT system that collectively constitutes the greenhouse facility's behavior. The greenhouse growers can obtain an overview of the essential greenhouse parameters for decision-making from the dashboard. 


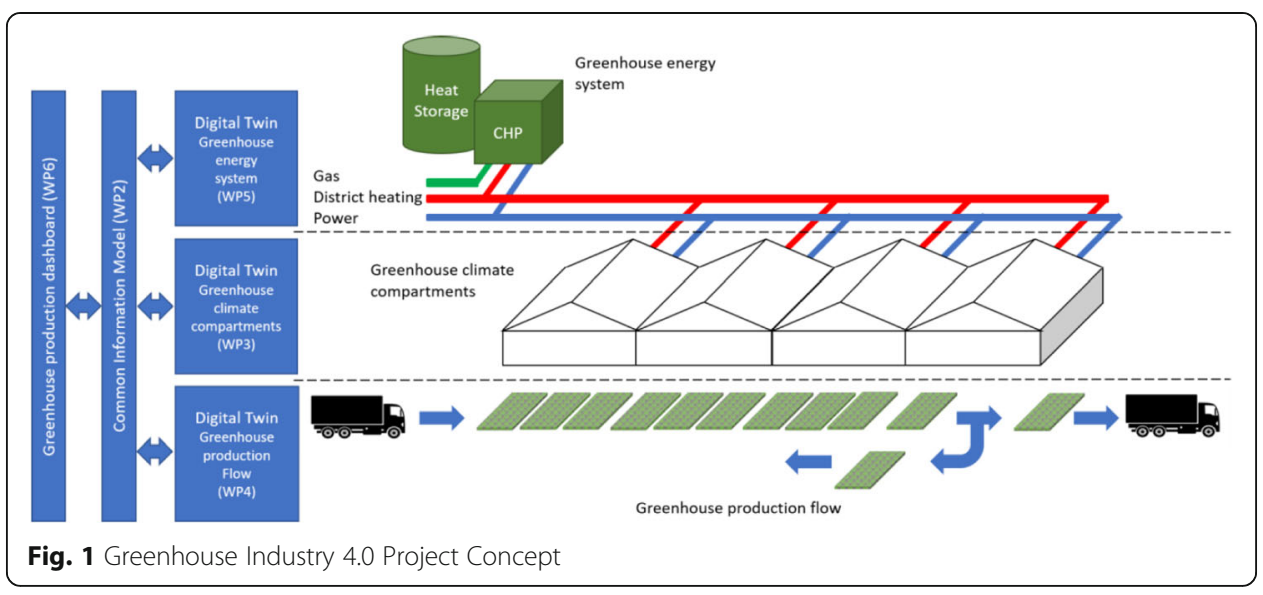

Digital twin of the greenhouse climate compartment

Several modeling approaches will be tested and evaluated using either an adaption of Unisim models or the development of new zone models to investigate the DT modeling hypothesis (Holst 2013). Requirements for zone modeling needs will be assessed and supplemented with an investigation of modeling and parameter estimation methodology for efficient and robust model performance. The parameter optimization platform ModestPy developed by SDU Center for Energy Informatics will be used for this investigation (Arendt et al. 2018b). The Modelica modeling framework will be used for zone model and functional mockup unit generation (Schweiger et al. 2018). Methodologies for integrating Unisim models and the additional models into InfoGrow will be evaluated and tested using the functional mockup interface. The DT of the greenhouse climate compartments will assess zone modeling needs through parameter and data identification. Based on the identification, a selection and validation of the estimation algorithm will be performed.

\section{Digital twin of the greenhouse production flow}

The DT of the greenhouse production flow will rely on the initial development of a multiagent simulation model for greenhouse production flow. Through the AI simulation platform AnyLogic, a generic multi-agent simulation model of the greenhouse production flow that includes all production steps will be created. The multi-agent simulation model will use inputs from the DT of the greenhouse climate compartment. The effects of changing production deadlines, quality assurance requirements, district heating demand, gas and electricity prices, and weather forecasts will be simulated and analyzed using the developed multi-agent simulation model. Potentials of energy efficiency and demand response participation will be investigated by simulating different production flow optimization scenarios. Based on the simulation, the effects of co-optimizing will be investigated according to influential factors. The DT will simulate energy efficiency and demand response potentials to discover potential bottlenecks in the production flow.

\section{Digital twin of the greenhouse energy system}

The greenhouse energy system's DT will initially map and identify the generic greenhouse energy system and specification of the actual case study. Following the 
identification, an interface for the CIM will be developed. Furthermore, based on the initial mapping, the energy system model will be generic and adaptable for the specific case study. The specific case study will be used for model parameter identification and validation on case study data from the regular operation. A generic greenhouse production facility's energy system will be the basis of a mathematical model to be adapted to specific cases. A generic model ensures the extendibility of the developed models. Furthermore, the modeling framework will be modular, using, e.g., Modelica, for ease of model adjustment and model integration in optimization algorithms through Functional Mock-up Interface. Together with the CIM, the model will constitute a digital representation of the current state of the energy system and have the capability to predict the demands and costs of future operation schedules. Modelica will be used as the generic modeling tool for implementing the CHP models and states, including current operation state, storage state, and CHP performance characteristics. The model will include outputs of power/heat production related to buy and sell prices from the grids and demands from the production plant to enable optimal CHP control. Parameter optimization will be used to estimate the sub-models involved in the CHP model and DT, depending on the meter and sensor data availability. The energy system DT will provide decision support for optimizing co-generation of heat and electricity based on predicted greenhouse demand, weather, electricity and district heating energy prices. Analysis and visualization of past and current plant efficiency and performance will be used for plant diagnostics functionality based on a comparison of ideal and real process performance indicators. Potential functionality for plant multi-objective optimal control for either greenhouse production optimization or participation in demand response event.

\section{Common information model}

To combine the DTs, a Common Information Model for the Greenhouse Industry (CIMGI) will be developed as an extension of the CIM for electricity transportation and distribution or as a separate entity based on CIM. Further, the definition of a communication protocol that offers a manifestation of the communication described by relations in the CIMGI is created to allow for an implementation in an OPC UA compliant software component. The CIMGI will propose an approach for standardizing information exchange between DTs in the I4.0 transformation of the greenhouse sector. The CIM will use an OPC-UA server with a user interface for connecting new future sensors and climate computers.

To combine the three developed DTs, the in-memory data grid Hazelcast has been identified as a viable solution for providing horizontal integration through shared topics. A horizontal integration approach using a dedicated communication subsystem was deemed favorable as it allows communication across the DTs developed in different subsystems, which can be efficiently removed or added. In Hazelcast, the DTs will utilize a publish/subscribe messaging model for communication. The shared topics are updated using message listeners with universally unique identifiers. Furthermore, the DTs are integrated with relevant production data that are stored in a relational database. Through SQL queries, the data relevant to the individual DTs is retrieved. The established relational database also holds historical data, which allows for running 
historical production and examine potentials for optimization and learning strategies that may be used for future production.

\section{Project partners}

The project is developed in collaboration with the following industrial partners: Danish Technological Institute, University of Southern Denmark's Center for Energy Informatics, Aarhus University Department for Food and Agroecology, ornamental nursery Hjortebjerg, ornamental nursery ByGrowers, ornamental nursery Knud Jepsen, Danish Horticulture, NB Data, Senmatic, Danish Cleantech Hub, and Energy Denmark. Each of the project partners contributes with their area-specific knowledge, which promotes a cross-disciplinary research solution. All project partners are introduced below, together with their primary areas of responsibility (Table 1).

\section{Project impacts}

The project's technical deliverables constitute five main parts: three DTs, a CIM supported by a communication protocol, and a web-based dashboard that collects the user interfaces of all the DTs into one single point of access for the greenhouse grower.

The project has focused on the Danish greenhouse industry. It can be divided into two main parts production of plant material in Danish greenhouses and providing technology for the industry in Denmark and international export markets. The plant producing industry is dependent on its international competitiveness. Using new innovative technology developed in the applied project will contribute significantly to enhancing the Danish growers' international readiness and competitiveness. Furthermore, the innovative tools are expected to attract young growers, thereby significantly impacting employment and knowledge gain in the horticultural greenhouse industry. In

Table 1 GHI4.0 project partners contribution

\begin{tabular}{|c|c|}
\hline Partner & Expertise \\
\hline $\begin{array}{l}\text { Center for Energy Informatics, University } \\
\text { of Southern Denmark }\end{array}$ & $\begin{array}{l}\text { An interdisciplinary research, development, and innovation center } \\
\text { that focuses on applying information technology to facilitate a } \\
\text { sustainable energy system. }\end{array}$ \\
\hline $\begin{array}{l}\text { Department of Plant Technology, The } \\
\text { Danish Technological Institute }\end{array}$ & $\begin{array}{l}\text { Has many years of experience in plant technology via projects and } \\
\text { research. }\end{array}$ \\
\hline $\begin{array}{l}\text { Department for Food and Agroecology, } \\
\text { Aarhus University }\end{array}$ & $\begin{array}{l}\text { The department for agroecology focuses on the interaction } \\
\text { between climate, soil, plants, animals, and people in agro- } \\
\text { ecosystems. } \\
\text { The Department of Food Science encompasses the entire food } \\
\text { chain and research towards food constituents' and health- } \\
\text { promoting effects. }\end{array}$ \\
\hline Greenhouse Industry Partners & Include the nurseries of Knud Jepsen, ByGrowers, and Hjortebjerg \\
\hline Danish Horticulture & $\begin{array}{l}\text { The Danish horticultural industry's trade association representing its } \\
\text { approximately } 500 \text { members' political interests. }\end{array}$ \\
\hline NB Data & $\begin{array}{l}\text { Has many years of development experience in planning software } \\
\text { for the greenhouse industry. }\end{array}$ \\
\hline Senmatic & $\begin{array}{l}\text { One of the first companies globally to market LED lighting as an } \\
\text { alternative to traditional horticultural lighting. }\end{array}$ \\
\hline Danish Cleantech Hub & $\begin{array}{l}\text { Provides the local platform and strong network necessary for } \\
\text { bringing Danish solutions into New York. }\end{array}$ \\
\hline Energy Denmark & $\begin{array}{l}\text { Energy Denmark is a market leader in electricity trading in Denmark } \\
\text { and, at the same time, an active market participant in the trade in } \\
\text { oil and gas products. }\end{array}$ \\
\hline
\end{tabular}


international competitiveness, the Danish horticultural industry has focused on reducing the carbon footprint of their products. GHI4.0 will aid in improving the Danish horticultural Industry's reputation as environmentally sustainable.

GHI4.0 will increase energy security for greenhouse production and support the production flow timeline and productivity in a broader perspective. Through the GHI4.0 findings, the greenhouse will get a tool to overview the use of energy, the energy system, energy prices, energy types etc., which will contribute to energy supply security. Furthermore, GHI4.0 will provide a tool to ensure the production timeline, aligned with the energy demand and supply. Collectively the tools will ensure a production optimized with the energy use. Greenhouse production has a high degree of flexibility in using various energy sources. The production, i.e., the plants, tolerate a high degree of dynamics in the climate. Combining the flexibility and the production tolerance with the right decisions, the grower can be an active player on the energy grid. The Danish greenhouse industry is already using several renewable energy sources. To see a substantial increase in the use of renewable energy sources, an overview of the energy flow and its consequence is needed. The developed DTs aim at becoming a standard for the greenhouse industry in Denmark and several other countries. Thereby aiding the greenhouse industry in transitioning towards fossil-free energy sources.

The Danish greenhouse sector has an energy consumption of $4.200 \mathrm{TJ}$, of which over $50 \%$ of the energy comes from non-renewable energy sources. GHI4.0 will improve the awareness and the readiness of the greenhouses to take on more responsibility and increase renewable energy use. Based on projects previously done, it is expected that it is realistic to save between 5 and $15 \%$ on the non-renewable energy sources in ornamental nurseries that utilize the new possibilities in GHI4.0. Realizing the energy saving will mean an energy reduction between 210 and $630 \mathrm{TJ}$ in the Danish greenhouse sector.

The DTs developed in GHI4.0 will also have the potential to include other aspects of optimizing greenhouse production. This could include, e.g., water usage management, pesticides, and water quality in greenhouse horticulture as problems with leaked pesticides and nutrition from the nursery have been gaining attention. As a platform, the DT can provide the needed technology for including knowledge and measures from water usage and water quality, which can help generate reports on the needed information.

\section{Conclusion}

The project aims to create a Greenhouse Industry 4.0 Digital Twin software platform for combining the Industry 4.0 technologies (IoT, AI, Big Data, cloud computing, and Digital Twins) as integrated parts of the greenhouse production systems. The project will provide a new disruptive approach for vertical integration and optimization of the greenhouse production processes to improve energy efficiency, production throughput, and productivity without compromising product quality or sustainability. An ecosystem of integrated digital twins extends the state-of-the-art by adopting a scalable distributed meta-model approach that interconnects Digital Twins in a production facility. This enables a collection of specialized Digital Twins to be linked together to describe and simulate all aspects of the production chain, i.e., overall production capacity, energy consumption, delivery dates, and supply processes. Applying the Industry 4.0 enabled Digital Twin concept in the Danish horticulture greenhouse industry allows evaluating 
the physical greenhouse facility's performance and the production processes through digital models and simulation. The developed Digital Twins will predict how the physical twin will perform under different operational conditions. Furthermore, the Digital Twin concept will support the co-optimization of the production schedule, energy consumption, and labor cost by considering influential factors, including production deadlines, quality grading, heating, artificial lighting, energy prices (gas and electricity), and weather forecasts. Through the established GHI4.0 project ecosystem of Digital Twins, the project promotes industrial greenhouse facilities actively participating in the electricity market. In turn, this can make the industrial greenhouse facilities increasingly competitive and sustainable while aiding in the balancing of the future electricity grid.

\section{Abbreviations}

GHI4.0: Greenhouse Industry 4.0; IOT: Internet of Things; Al: Artificial Intelligence; IT: Information Technologies;

CIM: Common Information Model; CIMGI: Common Information Model Greenhouse Industry; MPC: Model Predictive Control

\section{Acknowledgments}

Not applicable.

\section{Authors' contributions}

DAH devised the initial draft based on the original funding application. ZMA, JMA, ACL, CTV, and BNJ wrote the original funding application. All authors contributed with read-through commenting and approval of the final manuscript.

\section{Authors' information}

Any inquiry regarding the project, please contact the project coordinator, Jesper Mazanti Aaslyng; Any inquiry regarding the digital twin research, please contact Bo Nørregaard Jørgensen.

\section{About this supplement}

This article has been published as part of Energy Informatics Volume 4, Supplement 2 2021: Proceedings of the Energy Informatics.Academy Conference Asia 2021. The full contents of the supplement are available at https:// energyinformatics.springeropen.com/articles/supplements/volume-4-supplement-2.

\section{Funding}

The Greenhouse Industry 4.0 project is funded by the Danish Energy Technology Development and Demonstration Program (EUDP Project no 64019-0018).

\section{Availability of data and materials}

Not applicable.

\section{Declarations}

Ethics approval and consent to participate

Not applicable.

Consent for publication

Not applicable.

\section{Competing interests}

The authors declare that they have no competing interests.

\section{Author details}

${ }^{1}$ SDU Center for Energy Informatics, Mærsk McKinney Møller Institute, University of Southern Denmark, Campusvej 55 DK-5230 Odense M, Denmark. ²SDU Center for Health Informatics and technology, Mærsk McKinney Møller Institute, University of Southern Denmark, Campusvej 55, DK-5230 Odense M, Denmark. ${ }^{3}$ Danish Technological Institute, Taastrup, Denmark

Published: 24 September 2021

\section{References}

Afroz Z, Shafiullah GM, Urmee T, Higgins G (2018) Modeling techniques used in building HVAC control systems: a review. Renew Sust Energ Rev 83:64-84. https://doi.org/10.1016/j.rser.2017.10.044

AnyLogic (2017) Simulation software comparison. Available from: https://www.anylogic.com/blog/simulation-software-toolcomparison/. Accessed 18 May 2021 
Arendt K, Jradi M, Shaker HR, Veje C (2018a) Comparative analysis of white-, gray- and black-box models for thermal simulation of indoor environment: teaching building case study. the 2018 Building Performance Modeling Conference and SimBuild co-organized by ASHRAE and IBPSA-USA: ASHRAE

Arendt K, Jradi M, Wetter M, Veje C (2018b) ModestPy: an open-source python tool for parameter estimation in functional mock-up units. the 1st American Modelica Conference 2018: Modelica Association and Linköping University Electronic Press

Blum DH, Arendt K, Rivalin L, Piette MA, Wetter M, Veje CT (2019) Practical factors of envelope model setup and their effects on the performance of model predictive control for building heating, ventilating, and air conditioning systems. Appl Energy 236:410-425. https://doi.org/10.1016/j.apenergy.2018.11.093

Christensen K, Ma Z, Demazeau Y, Jørgensen BN (2020a) Agent-based modeling of climate and electricity market impact on commercial greenhouse growers' demand response adoption. 2020 RIVF International Conference on Computing and Communication Technologies (RIVF); 2020 14-15 Oct

Christensen K, Ma Z, Demazeau Y, Nørregaard Jørgensen B (2020b) Agent-based modeling for optimizing CO2 reduction in commercial greenhouse production with the implicit demand response. 6th IEEJ International Workshop on Sensing, Actuation, Motion Control, and Optimization, SAMCON 2020; 2020-03-14; Tokyo. https://hal.archives-ouvertes.fr/hal-03051 658/file/CCl122\%20\%28submitted\%29.pdf

Clausen A, Maersk-Moeller HM, Soerensen JC, Joergensen BN, Kjaer KH, Ottosen CO (2015a) Integrating commercial greenhouses in the smart grid with demand response based control of supplemental lighting. 2015 International Conference on Industrial Technology and Management Science; 2015/11: Atlantis Press

Clausen A, Maersk-Moeller HM, Soerensen JC, Joergensen BN, Kjaer KH, Ottosen CO (2015b) Integrating commercial greenhouses in the smart grid with demand response based control of supplemental lighting. Acsr Adv Comput 34:199-213

D’Addona DM, Ullah AMMS, Matarazzo D (2017) Tool-wear prediction and pattern-recognition using artificial neural network and DNA-based computing. J Intell Manuf 28(6):1285-1301. https://doi.org/10.1007/s10845-015-1155-0

Fisher PR, Heins RD (1996) The greenhouse care system: a decision-support system for height control and scheduling of potted flowering plants. Acta Hortic 417:41-45

Frank AG, Dalenogare LS, Ayala NF (2019) Industry 4.0 technologies: Implementation patterns in manufacturing companies. Int J Prod Econ 210:15-26

Frantz JM, Hand B, Buckingham L, Ghose S (2010) Virtual grower: software to calculate heating costs of greenhouse production in the United States. Hort Technol 20(4):778-785. https://doi.org/10.21273/HORTTECH.20.4.778

Haeri H, Horkitz K, Lee H, Wang J, Hardman T, Ratcliffe H et al (2018) Assessment of barriers to demand response in the northwest's public power sector. Bonneville Power Administration

Herrmann C, Thiede S, Kara S, Hesselbach J (2011) Energy oriented simulation of manufacturing systems - concept and application. CIRP Ann 60(1):45-48. https://doi.org/10.1016/j.cirp.2011.03.127

Holst N (2013) A universal simulator for ecological models. Ecol Inform 13:70-76. https://doi.org/10.1016/j.ecoinf.2012.11.001

Howard DA, Ma Z, Aaslyng JM, Jørgensen BN (2020) Data architecture for digital twin of commercial greenhouse production. 2020 RIVF International Conference on Computing and Communication Technologies (RIVF); 2020 14-15 Oct. 2020; Ho Chi Minh City, Vietnam. 2020 RIVF International Conference on Computing and Communication Technologies (RIVF): IEEE

Howard DA, Ma Z, Jørgensen BN (2021) Digital twin framework for energy efficient greenhouse industry 4.0. Ambient intelligence - software and applications; 07/10/2020-09/10/2020. Springer International Publishing, Cham

Huang Z, Yu H, Peng Z, Feng Y (2017) Planning community energy system in the industry 4.0 era: achievements, challenges and a potential solution. Renew Sust Energ Rev 78:710-721. https://doi.org/10.1016/j.rser.2017.04.004

Kjaer KH, Körner O, Huet J-M, Holst N, Pedersen JS, Aaslyng JM (2018) An integrated simulation and decision support system for greenhouse climate control (InfoGrow 2.0) based on an open source greenhouse modelling platform. Acta Hortic (1271):47-54

Kjaer KH, Ottosen CO, Jorgensen BN (2012) Timing growth and development of Campanula by daily light integral and supplemental light level in a cost-efficient light control system. Sci Hortic-Amst 143:189-196. https://doi.org/10.1016/j. scienta.2012.06.026

Kjaer KH, Ottosen C-O, Jørgensen BN (2011) Cost-efficient light control for production of two campanula species. Sci HorticAmst 129(4):825-831. https://doi.org/10.1016/j.scienta.2011.05.003

Körner O, Hansen JB (2012) An on-line tool for optimising greenhouse crop production. Acta Hortic 957:147-154

Körner O, Warner D, Tzilivakis J, Eveleens-Clark B, Heuvelink E (2008) Decision support for optimising energy consumption in European greenhouses. Acta Hortic 801:803-810

Kritzinger W, Karner M, Traar G, Henjes J, Sihn W (2018) Digital twin in manufacturing: a categorical literature review and classification. IFAC-PapersOnLine. 51(11):1016-1022. https://doi.org/10.1016/j.ifacol.2018.08.474

Ma Z, Billanes JD, Kjærgaard MB, Jørgensen BN (2017a) Energy flexibility in retail buildings: From a business ecosystem perspective. In: 14th international conference on the European energy market (EEM); 2017 6-9 June 2017. IEEE, Dresden

Ma Z, Friis HTA, Mostrup CG, Jørgensen BN (2017b) Energy flexibility potential of industrial processes in the regulating power market. the 6th International Conference on Smart Cities and Green ICT Systems

Ma Z, Jørgensen BN (2018) Energy flexibility of the commercial greenhouse growers: The potential and benefits of participating in the electricity market. 2018 IEEE Power \& Energy Society Innovative Smart Grid Technologies Conference (ISGT); 2018 19-22 Feb

Ma Z, Korsgaard J, Jørgensen B (2020) Optimization of greenhouse production process: an investigation of energy efficiency potentials. $365-70 \mathrm{p}$

Ma Z, Schultz MJ, Christensen K, Værbak M, Demazeau Y, Jørgensen BN (2019) The application of ontologies in multi-agent systems in the energy sector: a scoping review. Energies. 12(16):3200. https://doi.org/10.3390/en12163200

Markvart J, Kalita S, Nørregaard Jørgensen B, Mazanti Aaslyng J, Ottosen CO (2008) Intelligrow 2.0 - a greenhouse component-based climate control system. Acta Hortic (801):507-514

Mlecnik E, Parker J, Ma Z, Corchero C, Knotzer A, Pernetti R (2019) Policy challenges for the development of energy flexibility services. Energy Policy 111147

Morvaj B, Lugaric L, Krajcar S (2011) Demonstrating smart buildings and smart grid features in a smart energy city. Proceedings of the 2011 3rd International Youth Conference on Energetics (IYCE); 7-9 July 2011 
Müller T, Möst D (2018) Demand response potential: available when needed? Energy Policy 115:181-198. https://doi.org/10.1 016/j.enpol.2017.12.025

Qingnan Li ZM, Jørgensen BN (2016) Discussion on China's power sector reforms and where to next? The 13th European energy market conference, EEM 2016; Porto, Portugal

Roblek V, Meško M, Krapež A (2016) A complex view of industry 4.0. SAGE Open 6(2):2158244016653987

Rosen R, von Wichert G, Lo G, Bettenhausen KD (2015) About the importance of autonomy and digital twins for the future of manufacturing. IFAC-PapersOnLine. 48(3):567-572. https://doi.org/10.1016/j.ffacol.2015.06.141

Rytter M, Sørensen JC, Jørgensen BN, Körner O (2012) Advanced model-based greenhouse climate control using multiobjective optimization. Acta Hortic 957:29-35

Schweiger G, Heimrath R, Falay B, O'Donovan K, Nageler P, Pertschy R, Engel G, Streicher W, Leusbrock I (2018) District energy systems: modelling paradigms and general-purpose tools. Energy. 164:1326-1340. https://doi.org/10.1016/j.energy.2018. 08.193

Seow Y, Rahimifard S, Woolley E (2013) Simulation of energy consumption in the manufacture of a product. Int I Comput Integr Manuf 26(7):663-680. https://doi.org/10.1080/0951192X.2012.749533

Sørensen JC, Kjaer KH, Ottosen CO, Jorgensen BN (2016) DynaGrow - multi-objective optimization for energy cost-efficient control of supplemental light in greenhouses. Proceedings of the 8th International Joint Conference on Computational Intelligence, Ecta 1:41-8

Sørensen JC, Kjaer KH, Ottosen CO, Jørgensen BN (2019) DynaGrow: next generation software for multi-objective and energy cost-efficient control of supplemental light in greenhouses. In: Merelo JJ, Melício F, Cadenas JM, Dourado A, Madani K, Ruano A et al (eds) Computational Intelligence: International Joint Conference, IJCCI 2016 Porto, Portugal, November 911, 2016 Revised Selected Papers. Springer International Publishing, Cham, pp 25-44

Tao F, Cheng J, Qi Q, Zhang M, Zhang H, Sui F (2018) Digital twin-driven product design, manufacturing and service with big data. Int J Adv Manuf Technol 94(9):3563-3576. https://doi.org/10.1007/s00170-017-0233-1

Uhlemann THJ, Lehmann C, Steinhilper R (2017) The digital twin: realizing the cyber-physical production system for industry 4.0. Proc CIRP 61:335-340. https://doi.org/10.1016/j.procir.2016.11.152

Vanthoor B (2011) A model-based greenhouse design method [PhD Thesis]. Wageningen University, Wageningen

\section{Publisher's Note}

Springer Nature remains neutral with regard to jurisdictional claims in published maps and institutional affiliations.

\section{Submit your manuscript to a SpringerOpen ${ }^{\circ}$ journal and benefit from:}

- Convenient online submission

- Rigorous peer review

- Open access: articles freely available online

High visibility within the field

- Retaining the copyright to your article

Submit your next manuscript at $\boldsymbol{s p r i n g e r o p e n . c o m ~}$ 